\title{
Survey Utilisasi Spektrum Frekuensi Kota Makassar Untuk Aplikasi Jaringan Kognitif Sensor Nirkabel
}

\author{
Dahliah Nur ${ }^{1)}$, Nurlaila Umar ${ }^{2)}$, Alfiyah Dini ${ }^{2)}$, Salama Manjang ${ }^{3)}$, Dewiani ${ }^{3)}$, Wardi $^{3)}$ \\ ${ }^{1}$ Teknik Elektro, Politeknik Negeri Ujung Pandang \\ dahlia@poliupg.ac.id \\ ${ }^{2}$ Balai Monitor Spektrum Frekuensi Radio Kelas II Makassar \\ lela_umar@yahoo.com \\ alfiyah_dini@yahoo.com \\ ${ }^{3}$ Teknik Elektro, Universitas Hasanuddin \\ salamamanjang@unhas.ac.id \\ dewiani@unhas.ac.id \\ wardi@unhas.ac.id
}

\begin{abstract}
Penelitian ini mempelajari pola penggunaan spektrum di Makassar di pita frekuensi $430 \mathrm{MHz}$ sampai $3400 \mathrm{MHz}$. Tujuannya adalah untuk menemukan bagaimana spektrum radio dialokasikan ke berbagai layanan dan mengidentifikasi penggunaan pita-pita frekuensi aktif atau tidak aktif yang dapat diakses untuk penggunaan spektrum akses dinamis di masa akan datang khususnya untuk aplikasi jaringan kognitif sensor nirkabel. Hasil dari pengukuran spektrum yang dilakukan selama 5 hari kerja mengungkapkan bahwa sejumlah spektrum di Makassar pendudukannya sangat rendah di setiap saat. Tingkat pendudukan diukur sebagai jumlah spektrum yang terdeteksi di atas batas ambang daya yang diterima dan diperoleh rata-rata pendudukan spektrum 12.11\%. Hasil dari penelitian ini menunjukkan bahwa Makassar memiliki potensi besar untuk menggunakan teknologi spektrum akses dinamis seperti teknologi radio kognitif pada jaringan sensor nirkabel dan untuk mengakomodasi permintaan yang sangat besar untuk layanan nirkabel di masa depan. Namun, studi jangka panjang tentang survei spektrum ini masih perlu dilakukan untuk menentukan potensi pengguna sekunder (secondary user) pada jaringan yang memiliki utilisasi rendah atau tidak aktif.
\end{abstract}

Keywords: Pengukuran Spektrum, Radio Kognitif, Jaringan Sensor Nirkabel, Spektrum Akses Dinamis.

\section{PENDAHULUAN}

Teknologi Wireless Sensor Network (WSN) banyak digunakan untuk melakukan tugas pemantauan dan pengawasan. WSN adalah jaringan ad hoc self-organizing yang terdiri dari sejumlah node sensor yang digunakan secara sistematis atau acak [1]. Umumnya, aplikasi WSN memanfaatkan spektrum yang tidak berlisensi seperti Industrial, Scientific and Medical (ISM) dan Unlicensed National Information Infrastructure (UNII). Aplikasi nirkabel yang menggunakan pita spektrum ISM termasuk Bluetooth, WiFi, WiMAX, dan ZigBee, serta aplikasi lain seperti oven microwave dan telepon nirkabel. Dengan pertumbuhan yang luar biasa dari aplikasi nirkabel berbiaya murah yang memanfaatkan spektrum tidak berlisensi, dipastikan kinerja jaringan berbasis WSN secara keseluruhan akan menurun seiring dengan meningkat-nya utilisasi spektrum terutama masyarakat di daerah perkotaan.
Secara umum di Indonesia dan secara khusus di Makassar alokasi spektrum frekuensi radio diatur dalam Peraturan Menteri Komunikasi dan Informatika Republik Indonesia Nomor 25 Tahun 2014 [2], membagi keseluruhan sumber spektrum untuk berbagai layanan berlisensi sebagai pengguna ekslusif, seperti: siaran TV, siaran radio, perangkat seluler dan lain-lainnya. Pendekatan alokasi spektrum tetap (fix) semacam itu memang tidak menimbulkan gangguan diantara pengguna. Namun, hasil dari penggunaan spektrum radio tidak efisien. Beberapa pita frekuensi banyak yang sibuk, sementara pita frekuensi yang lainnya kurang digunakan bahkan tidak digunakan sama sekali [3]. Masalah muncul ketika ada inovasi baru layanan komunikasi nirkabel pita lebar seperti 5G dengan teknologi Fixed Wireless Access (FWA) yang perlu dialokasikan pada spektrum frekuensi.

Salah satu solusi yang paling menjanjikan untuk mengatasi masalah ini adalah teknologi radio kognitif (CR). Perangkat $\mathrm{CR}$ memiliki 
kemampuan untuk mengidentifikasi pita spektrum yang tidak berpenghuni untuk penggunaan sementara, dan mengosongkan spektrum bila diperlukan. Oleh karena itu, CR dipandang sebagai teknologi untuk mengatasi penggunaan sumber spektrum radio yang tidak efisien saat ini $[4,5]$.

Pemanfaatan teknologi radio kognitif pada jaringan sensor nirkabel sangat bergantung dengan utilisasi spektrum frekuensi. Survei utilisasi spektrum adalah salah satu alat penting untuk memetakan pemakaian spektrum serta memberi informasi penting kepada para pembuat kebijakan tentang pola penggunaan frekuensi dari berbagai layanan pada pita frekuensi yang berbeda. Sampai saat ini, beberapa survey pengukuran telah dilakukan di Beijing, Turki, Singapura, dan Eropa [6-9]. Dari pengukuran-pengukuran tersebut diperoleh hasil yang secara umum menunjukkan bahwa sebagian besar sumber daya spektrum yang telah ditetapkan layanannya jarang digunakan, sementara beberapa pita spektrum tertentu penuh sesak. Dalam tulisan ini, kami menggunakan data dari hasil pengukuran yang dilakukan oleh Balai Monitor Spektrum Frekuensi Radio Kelas II Makassar pada spektrum frekuensi $400 \mathrm{MHz}-3400 \mathrm{MHz}$ di Kota Makassar. Tujuan yang ingin dicapai dari tulisan ini adalah untuk mengetahui pita frekuensi yang sesuai untuk akses spektrum dinamis di masa depan seperti perangkat CRSN.

\section{PENGUKURAN DAN PROSEDUR PENGUKURAN}

Pengukuran dilakukan pada tanggal 13 17 Juni 2017 menggunakan sarana stasiun monitor frekuensi radio (SMFR) Balai Monitor Spektrum Frekuensi Radio Kelas II Makassar di wilayah Kota Makassar. Pengamatan dilakukan sekurang-kurangnya 2 (dua) jam/pita sub service dengan merekam kanal, level, serta waktu pendudukannya.

Alat yang digunakan dalam pengukuran ini adalah:

1. Wideband Reciver RS DDF 205

2. Antena RS HE 600 dan ADD 295

3. Notebook Argus Support

4. Kabel Coaxial

5. GPS

6. Power Supply

Pengukuran dilakukan pada frekuensi sebagai berikut:
Tabel 1. Alokasi Frekuensi Pengukuran

\begin{tabular}{l|l}
\hline \multicolumn{1}{c|}{ Frekuensi Kerja } & \multicolumn{1}{|c}{ Layanan } \\
\hline $430-470 \mathrm{MHz}$ & Seluler, radiolokasi \\
\hline $478-806 \mathrm{MHz}$ & Siaran TV \\
\hline $806-880 \mathrm{MHz}$ & Seluler (CDMA) \\
\hline $880-960 \mathrm{MHz}$ & Seluler (GSM) \\
\hline $1800-2400 \mathrm{MHz}$ & Seluler (LTE) \\
\hline $2520-2670 \mathrm{MHz}$ & $\begin{array}{l}\text { Layanan penyiaran } \\
\text { Satelit (BSS) }\end{array}$ \\
\hline $3300-3400 \mathrm{MHz}$ & $\begin{array}{l}\text { Akses wireless pita } \\
\text { lebar }\end{array}$ \\
\hline
\end{tabular}

\section{METODE PEKURAN DAN ANALISIS DATA}

Tingkat pendudukan spektrum adalah metrik yang paling banyak digunakan untuk mengukur penggunaan spektrum. Biasanya didefinisikan sebagai probabilitas kejadian dimana kuat sinyal yang diukur dari bandwidth frekuensi tertentu di atas ambang batas (threshold) yang telah ditetapkan $[6,10]$.

Memilih ambang batas terlalu rendah akan menghasilkan estimasi pendudukan spektrum yang lebih tinggi karena adanya noise yang dianggap sebagai sinyal. Di sisi lain, jika ambang batas dipilih terlalu tinggi, beberapa saluran dapat dianggap tidak berpenghuni meskipun mungkin ada beberapa layanan resmi yang beroperasi dengan daya rendah. Menurut literatur yang ada pada survei spektrum [10, 11], ambang batas $5 \mathrm{~dB}$ di atas noise floor dianggap sebagai nilai ambang batas tertinggi.

\section{HASIL DAN PEMBAHASAN}

Pada bagian ini, kami menyajikan hasil pendudukan spektrum pita frekuensi satu per satu.

Masing-masing gambar pendudukan spektrum terdiri dari tiga tahap. Sub-gambar atas menggambarkan daya yang diterima pada input antena versus frekuensi selama pengukuran tunggal, digunakan untuk menunjukkan bentuk gelombang sinyal yang diduduki dan juga untuk memastikan bahwa ambang batas (garis merah) dipilih dengan benar. Sub-tengah adalah prosentasi pendudukan spektrum frekuensi. Sub-gambar ketiga adalah gambar jenis air terjun (water fall) dengan tingkat pendudukan dibandingkan waktu dan frekuensi. Pendudukan frekuensi ditentukan saat tingkat daya yang diterima di antena melebihi ambang batas. 
Gambar 1 menunjukkan pendudukan dari spektrum $430 \mathrm{MHz}$ sampai $470 \mathrm{MHz}$ yang diukur di Makassar selama periode 2 jam dari pukul 11.00 am - $13.00 \mathrm{pm}$, frekuensi ini melayani radio konsesi/radio bergerak seperti perangkat walkie-talkie $(430-450) \mathrm{MHz}$, dan layanan CDMA (450 - 470) MHz. Prosentasi pendudukan pada pita ini sebesar $11.9375 \%$.

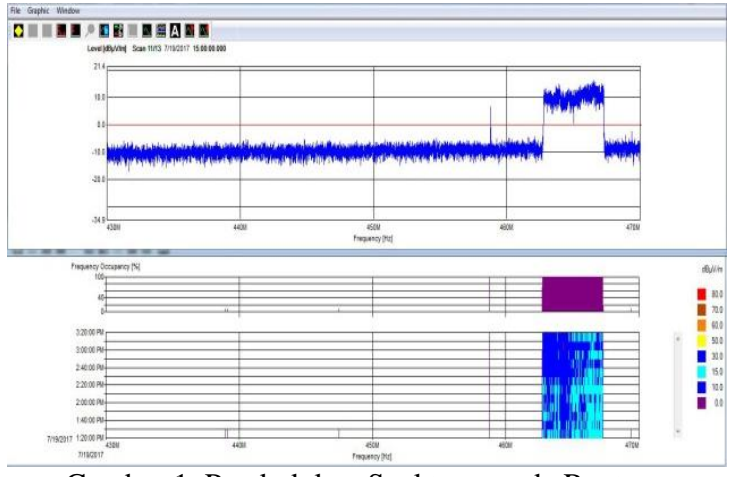

Gambar 1. Pendudukan Spektrum pada Rentang frekuensi $430 \mathrm{MHz}-470 \mathrm{MHz}$

Pada Gambar 2 menunjukkan pendudukan spektrum pada pita $478 \mathrm{MHz}$ sampai $806 \mathrm{MHz}$. Band ini dialokasikan untuk layanan penyiaran (TV analog PAL-DK, digital TV DTMB) dengan tingkat pendudukan sekitar $6,798236 \%$. Padatnya penggunaan spektrum tidak tercermin pada prosentasi pendudukan spektrum band ini, hal ini di karenakan nilai level threshold yang berbeda, dimana semakin tinggi frekuensi maka semakin tinggi pula nilai level thresholdnya, sehingga apabila berpatokan pada nilai level threshold pada frekuensi tertinggi (di atas $750 \mathrm{MHz}$ ) maka banyak pancaran frekuensi di bawah $750 \mathrm{MHz}$ yang tidak terbaca dalam prosentasi pendudukan spektrum.

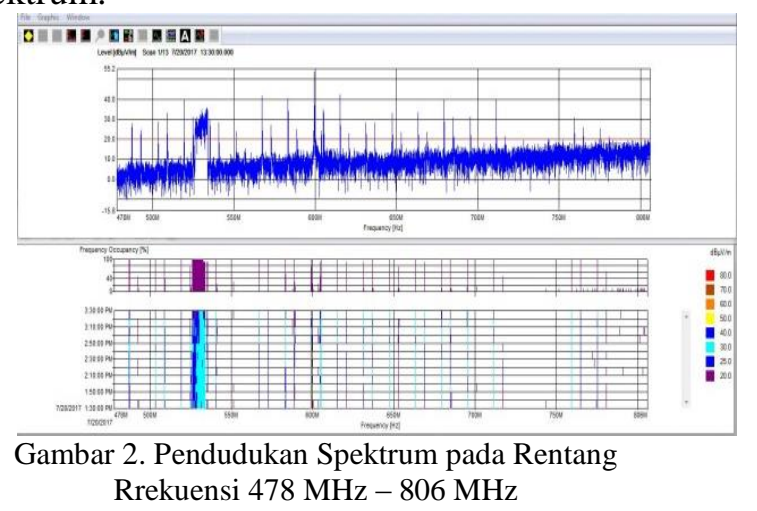

Namun apabila level threshold terendah yang digunakan maka noise floor pada frekuensi tinggi akan dibaca sebagai pendudukan frekuensi pada pita frekuensi ini.
Sehingga untuk pita ini sebaiknya dibagi 2 dalam proses pengambilan prosentasi pendudukan spektrum.

Gambar 3 menunjukkan penggunaan spektrum pita $806 \mathrm{MHz}$ sampai $880 \mathrm{MHz}$ yang dialokasikan untuk layanan seluler $800 \mathrm{MHz}$, layanan trunk radio dan layanan data bergerak. Spektrum rata-rata pita frekuensi ini adalah $13.68 \%$. Perhatikan bahwa pendudukan spektrum antara sisi uplink dan downlink seluler $800 \mathrm{MHz}$ tidak identik.

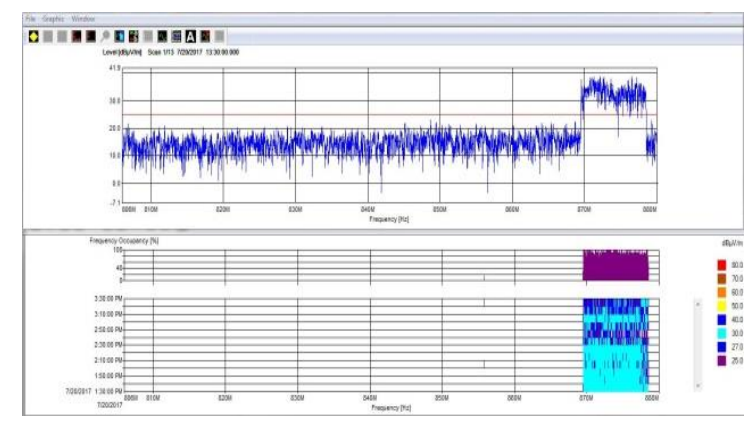

Gambar 3. Pendudukan Spektrum pada Rentang Frekuensi $806 \mathrm{MHz}-880 \mathrm{MHz}$

Gambar 4 pada rentang frekuensi 880 MHz-960 MHz, presentasi pendudukan spektrum pita trunking dan seluler (GSM) sebesar 26.8\%. Berbagai pola uplink dan downlink jaringan seluler bisa dijelaskan sebagai berikut: BTS terus-menerus menyiarkan saluran kontrol pada downlink, dengan daya pemancar yang lebih besar dibandingkan dengan terminal seluler, akan menghasilkan pola pendudukan spektrum yang hampir diduduki sepenuhnya. Kekuatan transmisi uplink untuk sistem seluler relative rendah maka pada downlink hampir tidak dapat dideteksi jika tidak ada komunikasi aktif.

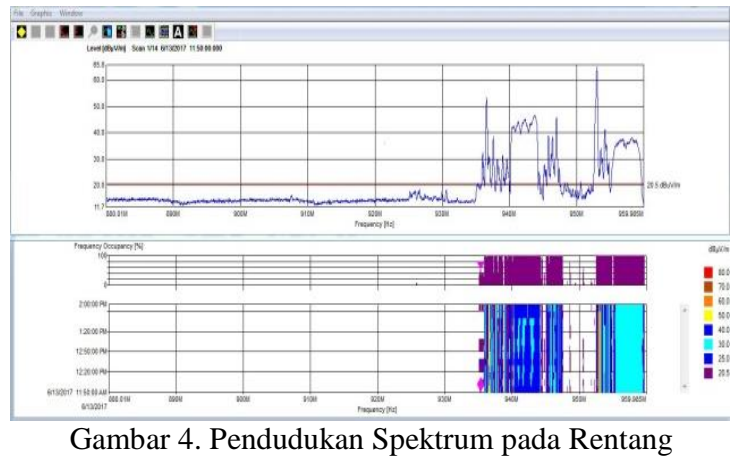
Frekuensi $880 \mathrm{MHz}-960 \mathrm{MHz}$

Gambar 5 menunjukan prosentasi pendudukan spektrum pada pita $1800 \mathrm{MHz}$ $2400 \mathrm{MHz}$ untuk layanan seluler. Hasil 
pengukuran diperoleh prosentasi pendudukan sebesar $26,8 \%$

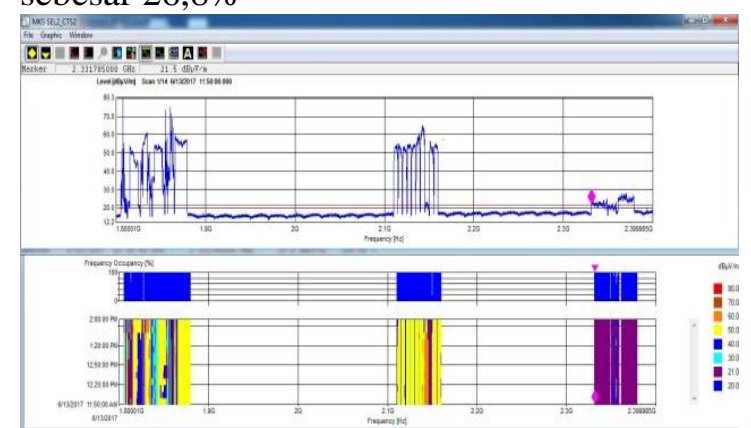

Gambar 5. Pendudukan Spektrum pada Rentang Frekuensi $1800 \mathrm{MHz}-2400 \mathrm{MHz}$

Gambar 6 menunjukkan pendudukan spektrum pada pita BSS $2520 \mathrm{MHz}$ 2670MHz. Terlihat bahwa prosentasi pendudukan pada pita ini adalah $0 \%$, dimana tidak ada pengguna teresterial pada band ini.

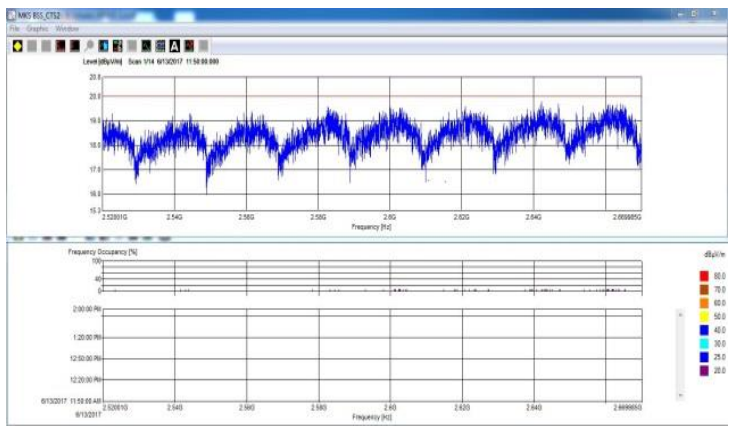

Gambar 6. Pendudukan Spektrum pada Rentang Frekuensi $2520 \mathrm{MHz}-2670 \mathrm{MHz}$

Hal serupa terjadi pada pendudukan spektrum BWA (3300-3400)MHz dengan prosentasi sebesar $0 \%$ dengan level threshold $\mathrm{dB} \mu \mathrm{V} / \mathrm{m}$, atau dengan kata lain tidak ada penggunaan spektrum frekuensi pada band ini.

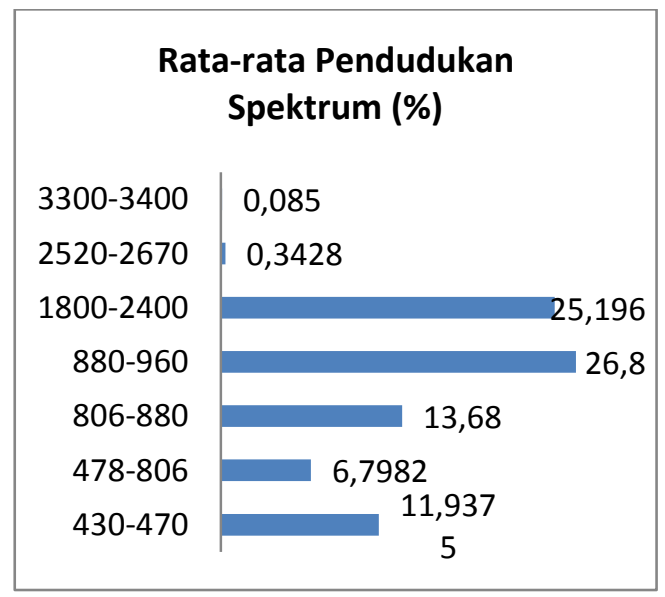

Gambar 7. Prosentasi Pendudukan Spektrum di Kota Makassar

\section{KESIMPULAN}

Dalam tulisan ini, kami mempelajari pola penggunaan spektrum di Makassar untuk pita frekuensi antara $450 \mathrm{MHz}$ sampai $3340 \mathrm{MHz}$. Tingkat pendudukan frekuensi secara keseluruhan terlihat pada gambar 7. Hasil dari pengukuran menunjukkan bahwa beberapa pita spektrum banyak digunakan sementara spektrum lainnya tidak digunakan sama sekali. Rata-rata pendudukan pada rentang frekuensi 430-3400 MHz di Kota Makassar sebesar $12.11 \%$.

Hasil pengukuran menunjukkan bahwa kecuali pita frekuensi yang dialokasikan untuk penyiaran dan telepon seluler, sebagian besar frekuensi yang dialokasikan kurang dimanfaatkan. Tingkat pendudukan untuk keseluruhan rentang frekuensi ini ditemukan hanya $12.11 \%$. Namun, survey pengukuran spektrum yang terkandung dalam laporan ini tidak dapat sepenuhnya digunakan untuk menilai kelayakan penggunaan layanan atau sistem alternatif dalam sebuah band. Untuk menilai kelayakan penggunaan layanan alternatif, studi pendudukan lebih lanjut perlu dilakukan, terutama pada pita-pita yang diidentifikasi kurang dimanfaatkan. Studi jangka panjang ini akan memungkinkan peneliti untuk mengidentifikasi tren musiman dan tren jangka panjang yang mungkin terjadi pada utilisasi pita-pita spektrum. Untuk kasus dimana sinyal pita tidak terdeteksi karena transmisi daya rendah, kepekaan receiver yang beroperasi pada pita tersebut harus diperhitungkan dalam menentukan ambang pendudukan spektrum sehingga perkiraan pendudukan menjadi lebih akurat. Untuk menilai variasi penggunaan spektrum di lingkungan dengan profil pengguna yang berbeda, kepadatan populasi yang berbeda dan karakteristik geografi yang berbeda, pengukuran paralel harus dilakukan di tempat yang berbeda baik di dalam maupun di luar ruangan dalam selang waktu yang lama. Penelitian lanjutan ini akan membantu peneliti untuk lebih mengenali secara akurat pita frekuensi dengan inisialisasi rendah atau tidak aktif dan memberi peluang pengembangan aplikasi teknologi kognitif radio seperti pada jaringan kognitif sensor nirkabel. 


\section{UCAPAN TERIMA KASIH}

Penulis mengucapkan terima kasih kepada Balai Monitor Spektrum Frekuensi Radio Kelas II Makassar atas dukungannya dalam penulisan kajian ini.

\section{REFERENSI}

[1] Kok Lim A. Yau, P. Komisarczuk, and P. D. Teal, "Cognitive Radio-based Wireless Sensor Networks Conceptual Design and Open Issues," The 2nd IEEE Workshop on Wireless and Internet Services (WISe 2009), 2009.

[2] Peraturan Menteri Komunikasi dan Informatika Republik Indonesia, "Tabel Alokasi Spektrum Frekuensi Radio Indonesia," ed: Kementrian Komunikasi dan Informatika, Nomor 25 Tahun 2014.

[3] FCC Spectrum Policy Task Force, "Report of the spectrum efficiency working group," ed: FCC, Technical Report 02-155, Nov 2002.

[4] J. Mitola and G. Q. Maguire, "Cognitive radio: making software radios more personal," IEEE personal communications, vol. 6, pp. 13-18, 1999.

[5] P. Zhang, Y. Liu, Z. Feng, Q. Zhang, Q. $\mathrm{Li}$, and $\mathrm{D}$. $\mathrm{Xu}$, "Intelligent and efficient development of wireless networks: A review of cognitive radio networks," Chinese Science Bulletin, vol. 57, pp. 3662-3676, 2012.

[6] J. Xue, Z. Feng, and K. Chen, "Beijing spectrum survey for cognitive radio applications," in Vehicular Technology Conference (VTC Fall), 2013 IEEE 78th, 2013, pp. 1-5.

[7] İ. Şeflek and E. Yaldı, "Spectrum occupancy measurements at university campus in Turkey," International Journal of Electronics and Electrical engineering vol. Vol. 5, No. 1, , 2017.

[8] M. H. Islam, C. L. Koh, S. W. Oh, X. Qing, Y. Y. Lai, C. Wang, et al., "Spectrum survey in Singapore: Occupancy measurements and analyses," in Cognitive Radio Oriented Wireless Networks and Communications, 2008. CrownCom 2008. 3rd International Conference on, 2008, pp. 1-7.
[9] V. Valenta, R. Maršálek, G. Baudoin, M. Villegas, M. Suarez, and F. Robert, "Survey on spectrum utilization in Europe: Measurements, analyses and observations," in Cognitive Radio Oriented Wireless Networks \& Communications (CROWNCOM), 2010 Proceedings of the Fifth International Conference on, 2010, pp. 1-5.

[10] Y. Chen and H.-S. Oh, "A survey of measurement-based spectrum occupancy modeling for cognitive radios," IEEE Communications Surveys \& Tutorials, vol. 18, pp. 848-859, 2016.

[11] R. Bureau, " Handbook on spectrum monitoring,"International Telecommunication Union (ITU), 2010, p. p. 168. 